\title{
Profile of Stereoscopic Acuity of School Children Aged 3 to 5 Years in the Yaounde 2 Sub-Division
}

\author{
Epée $\mathrm{E}^{1^{*}}$, Dohvoma VA ${ }^{1}$, Ebana $\mathrm{SR}^{1}$, Koki G1 ${ }^{1}$ Bege $\mathrm{MP}^{1}$, Mvilongo TC ${ }^{2}$, Akono ZE ${ }^{2}$ and Ebana Mvogo $\mathrm{C}^{1}$ \\ ${ }^{1}$ Faculty of Medicine and Biomedical Sciences, University of Yaound, Cameroon \\ ${ }^{2}$ Ophthalmology Department, Yaoundé Central Hospital, Cameroon
}

Submission: April 04, 2017; Published: June 06, 2017

*Corresponding author: Epée E, Faculty of Medicine and Biomedical Sciences, University of Yaoundé, Cameroon, P.0. Box: 11216 Yaoundé, Tel : +237-699-54-90-41, Email: epeeemilienne@gmail.com

\begin{abstract}
Summary
Aim: To establish the profile of the stereoscopic acuity of school children aged 3 to 5 years in the Yaounde 2 sub-division.

Methodology: We used a cross-sectional and descriptive study on a probabilistic sampling at 4 levels in nursery schools. Far vision was measured using the Pigassou chart, and the stereoscopic vision was assessed by means of TNO stereo test.

Results: We examined 365 children among whom 362 (99.2\%) had a stereoscopic acuity. Out of the latter, 10.4\% had an abnormal stereoscopic vision. The median values of the stereoscopic acuity were refined with the age. They varied from 120 " at 3 years, to 60 " at 4 and 5 years. The proportion of children having a stereoacuity $\leq 60$ " increased with the age; $32.3 \%$ at 3 years, $66.1 \%$ at 4 years, and $79.6 \%$ at 5 years.

Conclusion: The profile of the stereoscopic acuity in Cameroonian children does not have any specificity compared to the literature. The stereoacuity continues to be refined between age 3 and 5 to reach the threshold values of the adult. This examination is recommended for the screening of visual disorders in childhood.
\end{abstract}

Keywords: Stereoscopic vision; Stereoscopic acuity; School children; Cameroon.

\section{Introduction}

Binocular vision is the fundamental refinement of the visual function. It has 3 degrees: spontaneous vision, fusion, and stereoscopic vision. Stereopsis refers to the ability of the visual function to perceive depths and landscapes using binocular vision [1]. Stereoscopic acuity measured by the smallest detected retinal disparity [1], gives clear indication of the quality of binocular vision of an individual [2]. At adulthood, the absence of binocular vision can have an impact on professional orientation. People affected are excluded from certain professions as in aeronautics, marine and military careers: police, fire fighters. The very young child without binocular vision has at times difficulty learning how to walk, to read, or even how to write. A reduction in stereoscopic acuity can be associated to a number of vision problems as strabismus, amblyopia and anisometropia. As such, the measurement of stereoscopic acuity is frequently used to screen for visual dysfunction in children. It is more reliable than visual acuity in the screening of amblyopia [3].
Stereoscopic vision continues to evolve after birth. According to a number of authors, the maturation of stereoscopic vision is almost complete in children between 3 and 5 years [4-6]. In view of the importance of this characteristic, we aimed at establishing the profile of stereoscopic acuity of schooling children aged 3 to 5 years in the Yaounde 2 sub-division.

\section{Methodology}

\section{Participants selection}

We conducted a cross-sectional descriptive study from March 13 to May 15, 2015 in 10 nursery schools of the Yaounde 2 subdivision. Were included all schooling children aged 3 to 5 years who obtained written informed consent from their parents. Were excluded from our study all non-cooperating children after numerous trials or sick on the day of the descent, or refusal from parents. To obtain our sample size, we used probabilistic sampling in 4 degrees. Raffle draw permitted to choose Yaounde 2 sub-division amongst the seven $M$ foundi divisions. For the $2^{\text {nd }}$ 
degree which concerned the choice of the 10 schools amongst the 86 schools of the Yaounde 2 sub-division, we used Excel 2010. By random draw, a class was chosen per section. As for the $4^{\text {th }}$ degree, the choice of children in the classes. We agreed on a systematic draw of the first 20 pair numbers according to the order of the class list, which followed the order of registration in school. In total, we chose 600 children. We sent 600 questionnaires with notification letters and informed consent forms to the parents of the pupils chosen 3 days before our visit to the school.

\section{Data collection procedure}

This was done in 4 steps. Firstly, hetero-anamnesis of children from their parents, using the pre-prepared questionnaire filled at home by themselves. We looked for neonatal and ophthalmological past medical history. Then was general inspection performed with emphasis on eyes, looking for malformation, torticollis, nystagmus, apparent strabismus, or an abnormality of the cornea. After this we undertook, measurement of distance visual acuity with and without optic correction using Pigassou's scale placed 5 metres in front of the child. At the end came evaluation of stereoscopic vision using Stereo test TNO. The child with duo chromic lenses (red/green), the test placed at $40 \mathrm{~cm}$ away from his/her eyes, perpendicular to the visual axis, the different plates were moved in front of them so that they should identify. Significant reduction of distance visual acuity (RdVA) was defined by distance visual acuity, $d V A \leq 6 / 10$ in at least one eye or an anisoacuity $\geq 2$ line on Pigassou's scale stereoscopic acuity, $\mathrm{SA} \geq 240$ " corresponded to an abnormal or bad stereoscopic vision.

\section{Statistical Analysis}

Data collected was entered in a database created with CSPro 6.0 software and were exported to IBM SPSS 21 software. Tables and diagrams were designed using Excel 2010. Anova test was used to compare the stereo acuity between different age groups and Pearson's Chi ${ }^{2}$ test and Fischer Exact test to look for associated factors to bad stereoscopic vision. Significance was set at 0.05 .

\section{Results}

\section{Participation rate}

We sent 600 questionnaires together with informed consent forms to parents of selected pupils. We registered 374 forms amongst which 6 refusal and 3 absences. Our analysis was on 365 children in total; a participation rate of $60.8 \%$.

\section{Age distribution of the population}

Among the 365 children examined, 175 were girls (47.9\%) and 190 boys (52.1\%), with a sex-ratio of 1.1 in favour of boys. Our population was divided in 03 groups: 100 (27.4\%) children aged 3 years, 122 (33.4\%) aged 4 years, and 143 (39.2\%) aged 5 years (Figure1). The most represented age group was that of 5 years. The mean age was $4.2 \pm 0.81$ years.

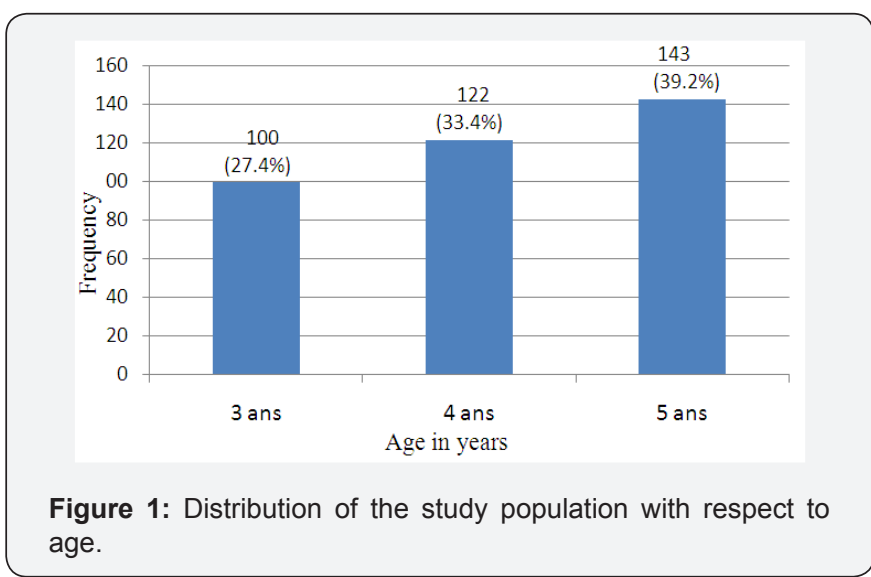

\section{Parental hetero-anamnesis of children}

In the past-history mostly mentioned were prematurity 11 cases, trauma 8 cases, and eye redness 6 cases.

\section{Ophthalmological exam}

At general examination, 4 children had strabismus, 2 others a vicious position of the head and one presented a nystagmus. We also found 2 children with optic corrections. Distance visual acuity was normal in 319 children (87.4\%), (Table 1). The children had a poor distance visual acuity, represented $12.6 \%$ of the study population.

Table 1: Distribution of the study population with respect to visual acuity values.

\begin{tabular}{|c|c|c|c|}
\hline \multirow{2}{*}{ Good dVA } & $\begin{array}{c}\text { Frequency } \\
\mathbf{n = 3 6 5}\end{array}$ & $\begin{array}{c}\text { Percentage } \\
\text { (\%) }\end{array}$ \\
\cline { 2 - 4 } & Isoacuity $\geq 7 / 10$ th & 302 & 82.7 \\
\hline $\begin{array}{c}\text { Anisoacuity of a } \\
\text { Pigassou's line } \\
\text { rdVA }\end{array}$ & $\begin{array}{c}\text { Acuity } \leq 6 \text { In at least } \\
\text { one eye }\end{array}$ & 41 & 4.7 \\
\hline & $\begin{array}{c}\text { Anisoacuity } \\
\geq 2 \text { Pigassou's lines }\end{array}$ & 5 & 1.4 \\
\hline & Total & 365 & 100 \\
\hline
\end{tabular}

\section{Stereoscopic vision evaluation}

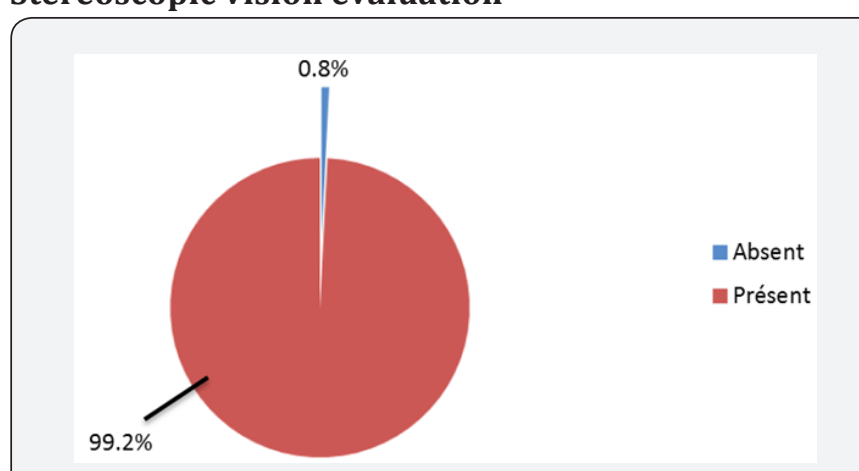

Figure 2: Proportion of children with a stereoscopic sense. 
In our study population, $99.2 \%$ (362 children) had the stereoscopic sense as represented by (Figure 2). In $03(0.8 \%)$ cases, we discovered an absence of stereoscopy; one in each agegroup. Among the 3 children (0.8\%), with ocular dominance, 2 had left eye dominance. The value of stereoacuity (SA) with the largest proportion was 60"; $56.1 \%$ (203) of the study population. We counted 102 children (28.2\%) with SA of 120 ". The least represented class was that of $15 ", 2$ (0.6\%) (Table 2). The proportion of children with SA $\leq 60$ " increased with age, 32 children (32.3\%) amongst those aged 3 years, 80 (66.1\%) in those aged 4 years, and 113 (79.6\%) amongst the group of children aged 5 years. This increase in percentages with age was statistically significant $(\mathrm{p}=0.000)$ (Figure 3 ). The tendency inverted with values of 120 " to 480 ", the proportions decreased with age. These differences were statistically significant with $p=0.000$. The median values of stereoacuity gradually sharpened with age. They varied between 120 " at 3 year, to $60 "$ at 4 and 5 years. This variation was statistically significant $(p=0.000)$.
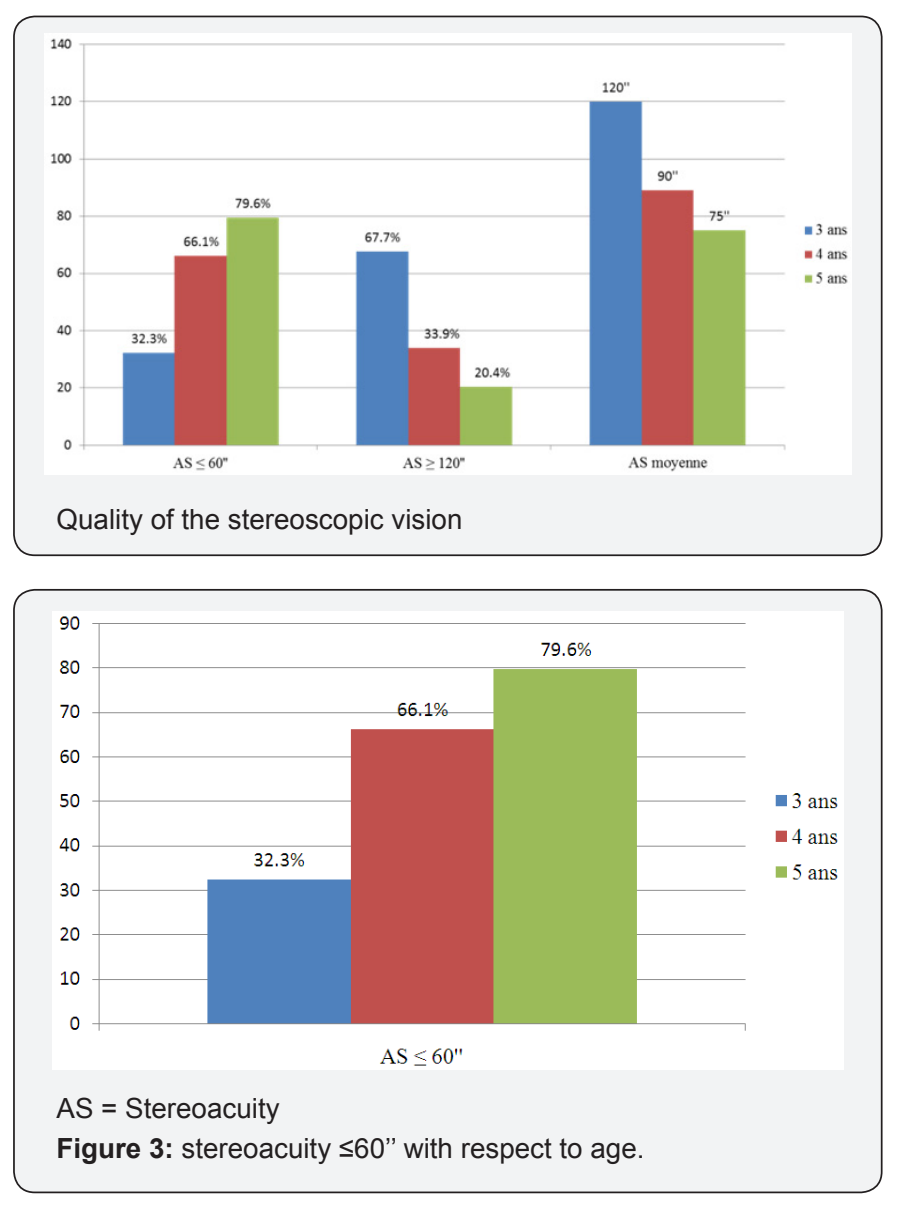

\section{Factors associated to poor stereoscopic vision}

In total, we found poor stereoscopic vision in 38 children, $10.4 \%$ of the study population (Table 2). According to the fact that age increased, the percentage of children with a normal stereoscopic vision increased and inversely, the proportion of children with poor stereoscopic vision decreased, significantly $(p=0.000)$. The significant Reduction in distance visual acuity (RdVA) and strabismus were the most encountered abnormalities in the group of children with poor stereoscopic vision ( $\geq 240$ "), with respective percentages of $47.4 \%$ and $10.5 \%$ (Table 3). After bivariate analysis, these two abnormalities were identified as being associated to poor stereoscopic vision with a $\mathrm{p}=0.000$ (Table 3).

Table 2: Values of stereoacuity with respect to age.

\begin{tabular}{|c|c|c|c|c|c|c|c|c|}
\hline $\begin{array}{c}\text { Age } \\
\text { (years) }\end{array}$ & \multicolumn{2}{|c|}{3} & \multicolumn{2}{|c|}{4} & \multicolumn{2}{|c|}{5} & & Total \\
\hline \multirow[t]{2}{*}{ SA (") } & \multicolumn{2}{|c|}{$n=100$} & \multicolumn{2}{|c|}{$n=122$} & \multicolumn{2}{|c|}{$n=143$} & \multicolumn{2}{|c|}{$n=365$} \\
\hline & n & $\%$ & n & $\%$ & $\mathbf{n}$ & $\%$ & $\mathbf{n}$ & $\%$ \\
\hline $15^{\prime \prime}$ & 0 & 0 & 1 & 0.8 & 1 & 0.7 & 2 & 0.6 \\
\hline $30 "$ & 0 & 0 & 9 & 7.4 & 11 & 7.8 & 20 & 5.5 \\
\hline $60 "$ & 32 & 32.3 & 70 & 57.9 & 101 & 71.1 & 203 & 56.1 \\
\hline $120^{\prime \prime}$ & 52 & 52.5 & 28 & 23.1 & 22 & 15.5 & 102 & 28.2 \\
\hline $240 "$ & 10 & 10.1 & 7 & 5.8 & 4 & 2.8 & 21 & 5.8 \\
\hline $480^{\prime \prime}$ & 2 & 2 & 2 & 1.7 & 1 & 0.7 & 5 & 1.4 \\
\hline $\begin{array}{c}>480^{\prime \prime} \\
(\mathrm{NM})\end{array}$ & 3 & 3 & 4 & 3.3 & 2 & 1.4 & 9 & 2.5 \\
\hline
\end{tabular}

Table 3: Factors associated to a poor stereoscopic vision.

\begin{tabular}{|c|c|c|c|}
\hline Abnormalities found & \multicolumn{2}{|c|}{ PSV $\mathbf{n = 3 8}$} & P value \\
\hline & $\mathbf{n}$ & $\mathbf{\%}$ & \\
\hline Prematurity & 3 & 7.9 & 0.096 \\
\hline Trauma & 1 & 2.6 & 0.589 \\
\hline Neonatal asphyxia & 0 & 0 & 1 \\
\hline Neonatal infection & 0 & 0 & 1 \\
\hline Neonatal jaundice & 0 & 0 & 1 \\
\hline Neonatal conjunctivitis & 1 & 2.6 & 0.198 \\
\hline Redness & 1 & 2.6 & 0.485 \\
\hline Ocular pruritus & 1 & 2.6 & 0.282 \\
\hline Nystagmus & 1 & 2.6 & 0.104 \\
\hline Strabismus*** & 4 & 10.5 & 0 \\
\hline Significant RdVA*** & 18 & 47.4 & 0 \\
\hline No abnormality & 8 & 21.1 & -- \\
\hline Total & 38 & 100 & \\
\hline
\end{tabular}

\section{Discussion}

The principal objective of this study was to establish the profile of stereoscopic vision of schooling children aged 3 to 5 years of the Yaounde 2 sub-division. Specifically, it aimed at determining the proportion of children with the stereoscopic sense, to measure the median values of stereoacuity and finally, to distinguish the factors associated to poor stereoscopic vision in our study population.

\section{Study Population}

A total of 600 forms were distributed and only 365 children were examined, giving a participation rate of $60.8 \%$. This rate 
was less than that obtained in the North department of France, during the 2011-2012 vision campaign organized by APESAL (Association de Prévention Et de Dépistage de troubles visuels Actions Locales) [7]. During this campaign in favour of children aged 2 years and a half to 3 years and a half, the participation rate was $80.05 \%$. This difference could be explained by the fact that the French health system encourages screening of childhood visual disorders. It could also be due to the level of alphabetisation of Cameroon $\left(71.3 \%\right.$ according to the $3^{\text {rd }}$ global population census and of habitat of Cameroon) [8], which is less than that of France (99\%, according to the Institute national de la statistique et des étudeséconomiques). Moreover, screening campaigns in France are scheduled well ahead of time and introduced in the calendar of targeted schools. Parents are informed many times for their participation. On the other hand, our study took place on a short period. The delay between distribution of forms and the field work was just 02 days, and no reminder was sent to parents. Also, we can add the skepticism of certain parents.

\section{Distribution of the study population according to age}

We targeted children aged 3 to 5 years. Given that the schooling rate of the populations of Yaounde is $88.8 \%$ according to the results of the Demographic and health investigation and having multiple indicators done in 2011 (EDS 2011) [9], the majority of children aged 3 to 5 years of Yaounde are in school at least 5 hours per day. That is why the site of recruitment chosen was nursery schools. In nursery schools, we generally find children from 3 years. However, many are those who will celebrate their birthday during the school year. Thus, in the small section, we can find children of 4 years, same for the midsection with children of 5 years. This could explain why in our study population, children aged 5 years were more represented $(39.2 \%)$, whereas the least represented were those aged 3 years $(27.4 \%)$, with a mean age of $4.12 \pm 0.81$ years.

\section{Stereoscopic vision evaluation/ Profile of stereoacuity Proportion of children with the stereoscopic sense in our study population}

According to our results, $0.8 \%$ of children didn't have the stereoscopic sense. The study Vision in Preschoolers (VIP), Ciner et al. [5] in the USA, on the stereoscopic acuity of children of 3 to 5 years, reported that $1.0 \%$ of children of the age range did not have the stereoscopic sense [5], results with corroborates ours. Moreover, he mentions that the proportion of children without the stereoscopic sense increased with age. Our sample respected this finding but this tendency was not statistically significant $(p=0.800)$, which could be due to our sample which is smaller than that of Ciner et al.

\section{Progression of SA with age/ quality of stereoscopic vision}

In our sample, measured with the stereo test TNO, the cumulative percentages of children with stereo acuity $\leq 60$ " was $32.3 \%$ at 3 years, $66.1 \%$ at 4 years and $79.6 \%$ at 5 years. This increasing tendency with age was statistically significant $(p=0.000)$. The TNO measures disparities till 15". Our results are similar to those of Ciner et al. [5] who using the Stereo Smile II whose finest measured disparity is 60 ". He compared the stereo acuity among age groups $(3,4$ and 5 years) and between the group of children with and without any disorder. His study population was made up of children from the Vision in Pre-schoolers programme. He reports that the proportions of children having reached that disparity increased significantly with age. Thus, $52.2 \%$ of the 3 years, $64.9 \%$ of the 4 years, and $71.4 \%$ of the 5 years were able to see in landscape with an SA $\leq 60$ " [5].The median SA of schooling children aged 3 to 5 years in Yaounde 2 varied from 120 " to 60", respectively from 3 years, to 4 and 5 years. This improvement with age was statistically significant $(p=0.000)$. In 1975 , Romano conducted his study using Titmus stereotest. He found median disparities from 200", 90 " and 40" respectively for 3 years, 4 years and 5 years [6]. Likewise, Birch et al. [10] in 2008, using the Randot stereo acuity test observed that the median values of SA sharpened with age, going from $100 "$ at 3 years, to $60 "$ at 5 years [10]. Thus, the median of SA with respect to age that we calculated sharpened with age, as described by the previous authors irrespective of the test used. Thus, the thresholds of SA for children of 3 to 5 years are very close to those found in adults suggesting therefore the maturation of stereoscopic vision is almost complete in children of that age range.

\section{Proportion of children with poor stereoscopic vision}

The number of children per age group, with poor stereoscopic vision, progressively significantly decreased with age increase. Fifteen percent of the population aged 3 years presented with a poor stereoscopic vision, $10.7 \%$ of 4 years, and $4.9 \%$ of 5 years $(\mathrm{p}=0.000)$. Ciner suggested the same variation in $2014: 29.6 \%$ at 3 years, $22.5 \%$ at 4 years, and $19.2 \%$ at 5 years [5]. The greatest proportions registered by his group could be due to the fact that his study population was far greater than ours, and had a large number of children suffering from at least one vision disorder which could hamper stereopsis.

\section{Factors associated to abnormal stereoscopic vision}

We detected 4 cases of strabismus. All of them had a poor stereoscopic vision, representing $10.5 \%$ of children with abnormal stereoscopic vision. An association was established between strabismus and abnormal stereoscopic vision $(p=0.000)$. This corroborates what many authors have described $[5,11]$. Sharma et al conducted a case-control study. They compared the SA of strabismus patients to that of a control. They showed a significant $(\mathrm{p}<0.001)$ poor stereopsis in the strabismus patients [11].The presence of a reduction in distance visual acuity (RdVA) was an associated factor to poor stereoscopic vision $(\mathrm{p}=0.000)$. This association is in the same line with reports from Ciner in 2014. Indeed, he found values of $\mathrm{SA} \geq 240$ " in $40.7 \%$ of children with a reduction in distance visual 
acuity $(\mathrm{p}<0.05)$ [5]. Amongst the children with poor stereo acuity, we identified 3 premature births (7.9\%). According to our findings, prematurity does not influence stereoscopic vision ( $p>0.05$ ). In 2000, Hard et al. [12] worked on a population of 51 premature children with mean age of $7.2 \pm 2.1$ years. He showed that this population had an important prevalence of vision disorders, such as altered stereoscopic vision, associated or not to strabismus. Hard counted 7 children with a pathological stereoacuity, among the 31-extreme premature (GA<28 weeks), giving a prevalence of $22.6 \%$ [11]. This disagreement between the two studies could be explained by our sample size. It is small and the risk groups, notably the premature children, were not sufficiently represented.

\section{Conclusion}

The profile of stereoacuity in Cameroonian children does not present any specificity with respect to literature. Stereoacuity continues to sharpen between 3 and 5 years to reach adult threshold values. This test is recommended for the screening of childhood vision disorders for it is more reliable than the measurement of visual acuity in the screening of morbidities such as strabismus and amblyopia.

\section{References}

1. Orssaud C (2006) Vision binoculaire. Encycl Méd Chir (Editions) Scientifiques et Médicales Elsevier SAS. Paris tous droits réservés). Ophtalmologie 21 : 545-A-25.
2. Ohlsson J, Villarreal G, Abrahamsson M, Cavazos H, Sjöström A, et al. (2001) Screening merits of the Lang II.Frisby.Randot. Titmus and TNO stereo tests. J AAPOS Oct 5(5): 316-322.

3. Farvardin M, Afarid M (2007) Evaluation of stereo tests for screening of amblyopia. Iranian Red Crescent Medical Journal 9(2): 79-86.

4. Fox R, Patterson R, Francis EL (1986) Stereoacuity in young children. Invest Ophthalmol Vis Sci 27(4): 598-600.

5. Ciner EB, Ying GS, Kulp MT, Maguire MG, Quinn GE, et al. (2014) Stereoacuity of preschool children with and without vision disorders. Optom Vis Sci 91(3): 351-358.

6. Romano PE, Romano JA, Puklin JE (1975) Stereoacuity development in children with normal binocular single vision. Am J Ophthalmol 79(6): 966-971.

7. Bilan de campagne visuelle 2011-2012 Département du Nord. Association de Prévention et d'Education Sanitaire Actions Locales.

8. (2005) Bureau Central des Recensement et des Etudes des Populations. $3^{\text {ème }}$ Recensement Global de la Population et de l'Habitat du Cameroun.

9. 2011 Enquête Démographique et de Santé et à Indicateurs Multiples.

10. Birch E, Williams C, Drover J, Fu V, Cheng C, et al. (2008) Randot Preschool StereoacuityTest: Normative data and validity. JAAPOS 12 (1): 23-26.

11. Sharma P, Saxena R, Narvekar M, Gadia R, Menon V (2008) Evaluation of distance and near stereo acuity and fusionalvergence in intermittent exotropia. Indian J Ophtalmol 56(2): 121-125.

12. Hard AL, Niklasson A, Svensson E, Hellström A Visual function in school-aged children born before 29 weeks: a population-based study. Dev Med Child Neurol 4292: 100-105.

\section{Your next submission with Juniper Publishers} will reach you the below assets

- Quality Editorial service

- Swift Peer Review

- Reprints availability

- E-prints Service

- Manuscript Podcast for convenient understanding

- Global attainment for your research

- Manuscript accessibility in different formats ( Pdf, E-pub, Full Text, Audio)

- Unceasing customer service

Track the below URL for one-step submission https://juniperpublishers.com/online-submission.php 